\title{
The Effect of Rutin on Antioxidant and Anti-inflammation in Streptozotocin-induced Diabetic Rats
}

*Correspondence to: Jeune $\mathrm{KH}_{\text {, }}$ Tel: +82-53-810-3571 Fax: +82-53-810-4681 E-mail: khjeune@yu.ac.kr

Received April 14, 2013

Revised June 10, 2013

Accepted June 12, 2013

\author{
Yoon Jeong Lee ${ }^{1,2}$, Kyung Hee Jeune ${ }^{1, *}$ \\ ${ }^{1}$ Department of Life Sciences, Yeungnam University, Gyeongsan 712-749, Korea, \\ ${ }^{2}$ Department of Optometry \& Vision Science, Kyungwoon University, Gumi 730-739, Korea
}

\begin{abstract}
The study examined the antioxidant activities and anti-inflammatory effects of rutin from the streptozotocin (STZ)-induced diabetic rats. Results revealed that the levels of plasma glucose and serum glucose were remarkably higher in the STZ-treated group compared to other groups and were significantly reduced in the STZ+rutin treated group compared to the STZ-treated group. In terms of weight, it significantly increased in all experimental groups during the experiment period except for STZ-induced diabetic group. The weight of the STZ-treated group was remarkably reduced compared to other groups. Regarding the weight of each body organ, the STZ-treated group showed higher organ weight compared to the other groups while STZ+rutin-treated group showed significantly reduced kidney and liver weights compared to those of STZ-treated group. In the pancreas tissue of the STZ-treated group, $\beta$-cell destruction and vacuolization were observed. Inflammation in the heart, liver, kidney, and retina tissues were also vividly recorded. In the STZ+rutin administered group, the heart and retina tissues were shown to be preserved normally while the liver and kidney tissues showed reduced histopathology in general compared to the STZ-treated group. Conclusionally, the rutin has the effect on the antioxidant activities and anti-inflammation in the STZ-induced diabetic rats.
\end{abstract}

Key Words: Rutin, Diabetic rats, Streptozocin, Antioxidant, Anti-inflammation

\section{INTRODUCTION}

Diabetes is a serious metabolic disease that is accompanied by various complications which cause high mortality rates. Due to increasing aged populations, high calorie diet, obesity, and lack of exercise, millions of the world populations are suffering from this serious disease (Simpson et al., 2003). Moreover, according to the World Health Organization, approximately 300 million people will suffer from diabetes by 2025 (World Health Organization/International Diabetes Federation, 1999). Diabetes is a disease that accompanies long-term hyperglycemia and metabolic disorders caused by insufficient physiological function of insulin or due to the lack of insulin secretion in the $\beta$-cell of the pancreas islet of Langerhans or reduction/absence of receptor for the insulin target cell. Thus, diabetes displays a variety of pathological physiology (Rayfield \& Ishimura, 1987). Also, diabetes accompanies many complications due to the abnormal control of glycometabolism and lipid metabolism. As the concentration levels of blood lipoprotein and free fatty acid increase, cardiovascular diseases such as hyperlipidemia and coronary-artery disease appear while causing complications like retinopathy, nephropathy, neurosis, nephrotoxicity and coma due to hyperglycemia (West et al., 1983). Such diabetic complications are considered to be triggered by a high level of oxidative stress (Baynes, 1991) and understood to cause excessive creation of reactive oxygen species and reduced effect of antioxidant defense system (Coppey et al., 2001). Moreover, diabetic complications are interrelated to inflammatory reaction because secretion of inflammatory factors from

This research was supported by the Yeungnam University research grants in 2011.

@ This is an open-access article distributed under the terms of the Creative Commons Attribution Non-Commercial License (http://creativecommons.org/licenses/by-nc/3.0) which permits unrestricted noncommercial use, distribution, and reproduction in any medium, provided the original work is properly cited.

Copyrights @ 2013 by Korean Society of Microscopy 
various cells is accelerated under a hyperglycemia state and the formation and secretion of acute response factors are induced in fat cells (Guha et al., 2000; Lin et al., 2001; Aronson et al., 2004). The secreted inflammatory factors are involved not only in complications like cardiovascular disease (CallesEscandon \& Cipolla, 2001; Dandona et al., 2003; Tracy, 2003; Widlansky et al., 2003) but also in microalbuminuria, such as microangiopathy (Gomes \& Nogueira, 2004), and diabetic retinopathy (Izuora et al., 2005).

Recently, the correlation between inflammatory response and diabetes was examined and Zhou et al. (2010) found two genes that could control inflammation and diabetes, simultaneously. This study reported that hyperglycemia was repressed when the secretion of interleukin (IL)-1 or cytokine related to inflammation was impeded by the action of these genes in cells. Today, many synthetic drugs are available as a remedy for diabetes; however, more interest is focused on plant extracts or components extracted from plants since these are considered to be relatively safe as they are natural antioxidants with fewer risks of side effects (Craig, 1999).

Rutin (International Union of Pure and Applied Chemistry name: 2-(3,4-dihydroxyphenyl)-5,7-dihydroxy-3-[ $\alpha$-Lrhamnopyranosyl-( $1 \rightarrow 6)-\beta$-D-glucopyranosyloxy]-4Hchromen-4-one) is one of the phenolic compounds and flavonoid glycosides mainly found in flowers and fruits. It was first extracted from Ruta graveolens and since then, has been known to be broadly spread in nature from buckwheat, orange, graph, lemon, lime, peach, berry, etc. (Kreft et al., 1999; Huang et al., 2012). Rutin, a flavonoid, has been reported to possess dynamic pharmacological functions, such as antioxidant, anti-bactericidal, antiviral (Potter, 1997; RiceEvans \& Packer, 1998), antitumor (Deschner et al., 1991), anti-inflammatory (Aleksandrov et al., 1986), anti-diarrhea (Di Carlo et al., 1993), anti-mutagenic (Bear \& Teel, 2000), myocardial protection (Pozin et al., 1996), immunomodulator (Chen et al., 2000), and hepatoprotective (Janbaz et al., 2002) functions. More importantly, many studies have been conducted to prove the efficiency of rutin's pharmacological functions as an antioxidant (Gao et al., 2002; Nagasawa et al., 2003a, 2003b; Kamalakkannan \& Prince, 2006).

In this study, the hypoglycemic effects by the antioxidant activities of rutin among the streptozotocin (STZ)-induced diabetic rats were examined along with the hematological and histopathology-changing aspects in the pancreas, heart, liver, kidney, spleen, and retina, organs related to diabetic complications, to measure anti-inflammatory effects.

\section{MATERIALS AND METHODS}

\section{Animals and Reagents}

For the test, 8-week old male Sprague-Dawley rats were taken from Hyochang Science Co., Ltd. (Daegu, Korea) and raised for a week to help them adapt to the experiment setting before conducting the experiment. The rats were raised in an animal laboratory that maintained $50 \pm 10 \%$ of humidity and $25 \pm 1^{\circ} \mathrm{C}$ of temperature and 12-hour controlled light/dark cycle through an automatic light controller. Also, water and feed were supplied for free intake. All reagents including STZ (N-(methylnitrosocarbamoyl)- $\alpha$-D-glucosamine) and rutin (quercetin-3-rutinoside) were purchased from Sigma-Aldrich Inc. (St. Louis, MO, USA).

\section{Diabetes Induction and Rutin Administration}

To induce diabetes, the rats were fasted for 12 hours and 65 $\mathrm{mg} / \mathrm{kg}$ of STZ dissolved in $0.1 \mathrm{M}$ citrate buffer ( $\mathrm{pH} 4.5$ ) was intraperitoneally administered. The rats were fasted again for 12 hours, 6 days after administering STZ and the level of blood glucose was measured by drawing whole blood from the tail vein. Then, a rat whose level of blood glucose was more than $350 \mathrm{mg} / \mathrm{dL}$ was screened for further experiment. The blood glucose was measured by using a glucometer (Accu-Check Go Kit [Model GS], Roche, Germany).

For the experiment, the rats were divided into three groups, such as normal group (normal, $\mathrm{n}=5$ ), STZ-induced diabetic group (STZ, $n=4)$, rutin-treated group after diabetes induction (STZ+rutin, $n=7$ ), and rutin-treated group (rutin, $\mathrm{n}=6$ ). For STZ+rutin-treated group and rutin-treated group, $5 \mathrm{mg} / \mathrm{kg}$ of rutin dissolved in soybean oil was orally administered at the same time every day for a week after inducing diabetes (Table 1).

\section{Measurement of Body Weight and Organ Weight}

The change in weight in body and organs like pancreas, heart, liver, kidney, and spleen during the experiment period was measured. After rutin treatment, the rats were anesthetized with $99.0 \%$ of diethyl ether and their weights were measured. Also, after taking blood from the abdominal aorta, pancreas, heart, liver, kidney, and spleen, the weight of the five organs, except for the eyes was measured.

\section{Blood Glucose Measurement and Hematological Analysis} The changes in blood glucose and functional changes in each organ were examined. The level of blood glucose was measured using a glucometer (Accu-Check Go Kit [Model

Table 1. Classification of experimental groups

\begin{tabular}{|c|c|c|}
\hline \multicolumn{2}{|c|}{ Group } & \multirow{2}{*}{$\begin{array}{c}\text { Characteristic } \\
0.1 \text { M citrate buffer }(\mathrm{pH} 4.5)\end{array}$} \\
\hline Normal & $\mathrm{n}=5$ & \\
\hline STZ & $\mathrm{n}=4$ & $\mathrm{STZ} 65 \mathrm{mg} / \mathrm{kg}$ \\
\hline STZ+rutin & $\mathrm{n}=7$ & $\mathrm{STZ} 65 \mathrm{mg} / \mathrm{kg}+\mathrm{rutin} 5 \mathrm{mg} / \mathrm{kg}$ \\
\hline Rutin & $\mathrm{n}=6$ & Rutin $5 \mathrm{mg} / \mathrm{kg}$ \\
\hline
\end{tabular}

STZ, streptozotocin. 
GS]). The blood was left in room temperature for 30 minutes; serum was then separated by conducting centrifugation with 3,000 rpm for 15 minutes. With the separated serum, values of glucose for the function of pancreas, glutamic oxalaceic transaminase (GOT), glutamic pyruvic transaminase (GPT), and alkaline phosphatase (ALP) for the function of liver, and blood urea nitrogen (BUN) and creatinine for the function of kidney were measured.

\section{Histological Observation}

The general formation or change in the removed organs was accessed. The removed pancreas, heart, liver, kidney, spleen, and eyes were fixed in $10 \%$ of phosphate buffered (neutral) formalin, cleansed through running water, dehydrated by gradually increasing the concentration of alcohol, removed extra alcohol by xylene and embedded. The paraffin block was sectioned in $4 \sim 5 \mu \mathrm{m}$ thickness by using a microtome (Model 45; Lipshaw, Pittsburgh, PA, USA) to make a slide and then it was dyed with hematoxylin-eosin and observed with a light microscope (BH-2, Olympus; Tokyo, Japan).

\section{Statistical Method}

For the statistical analysis, with a significant level of 95\% confidence interval, data was computed using one-way ANOVA using SPSS Windows ver. 14.0 (SPSS Inc., Chicago, IL, USA).

\section{RESULTS}

\section{Blood Glucose Measurement}

Blood glucose measurement is shown in Table 2. The con- centration levels of plasma glucose and serum glucose in the STZ-induced diabetic group were noticeably higher compared to those of other groups $(\mathrm{p}<0.05)$. Values derived from $\mathrm{STZ}+$ rutin-treated group were not reduced as much as the values obtained from the normal and rutin-treated groups. However, such values were significantly reduced compared to the values derived from the STZ-induced diabetic group $(\mathrm{p}<0.05)$.

\section{Measurement of Body Weight and Organ Weight}

Results derived from body weight and organ weight measurement are shown in Table 3. During the experiment period, weight of the rats significantly increased in all experimental groups except for the STZ-induced diabetic group. However, the weight of the STZ-induced diabetic group decreased noticeably compared to that of the normal, $\mathrm{STZ}+$ rutin-treated, and rutin-treated groups $(\mathrm{p}<0.05)$. For the weight of each organ, the STZ-induced diabetic group showed high values compared to the other groups, and the weight of the STZ+rutin treated group decreased compared to the STZ-induced diabetic group. In terms of the weight of organs, significant changes were found in the weights of the liver and kidney $(\mathrm{p}<0.05)$.

\section{Hematological Analysis}

The result on the index analysis for the functional changes of each organ is shown in Table 4. According to the result, all values obtained from the STZ-induced diabetic group were noticeably increased compared to the values from other groups $(\mathrm{p}<0.05)$. Values derived from the STZ+rutin group

Table 2. Change of plasma glucose and serum glucose levels

\begin{tabular}{ccccc}
\hline Parameter $(\mathrm{mg} / \mathrm{dL})$ & Normal $(\mathrm{n}=5)$ & STZ $(\mathrm{n}=4)$ & STZ+rutin $(\mathrm{n}=7)$ & Rutin $(\mathrm{n}=6)$ \\
\hline Plasma glucose & $146.75 \pm 10.23^{\mathrm{a}}$ & $468.75 \pm 65.76^{\mathrm{b}}$ & $232.20 \pm 61.72^{\mathrm{c}}$ & $149.75 \pm 27.63^{\mathrm{a}}$ \\
Serum glucose & $120.00 \pm 30.42^{\mathrm{a}}$ & $375.50 \pm 53.03^{\mathrm{b}}$ & $172.67 \pm 41.42^{\mathrm{c}}$ & $128.00 \pm 19.52^{\mathrm{a}}$ \\
\hline
\end{tabular}

Statistical analysis was by a one-way ANOVA with Tukey's test. All values are mean \pm standard error for rats in each group. Values with different superscripts are significantly different $(\mathrm{p}<0.05)$. STZ, streptozotocin.

Table 3. Change of body weight and each organ weight levels

\begin{tabular}{lcccc}
\hline \multicolumn{1}{c}{ Parameter $(\mathrm{g})$} & Normal $(\mathrm{n}=5)$ & STZ $(\mathrm{n}=4)$ & STZ+rutin $(\mathrm{n}=7)$ & Rutin $(\mathrm{n}=6)$ \\
\hline Initial body weight & $265 \pm 12$ & $270 \pm 14$ & $272 \pm 12$ & $267 \pm 7$ \\
Final body weight & $360 \pm 17^{\mathrm{a}}$ & $255 \pm 13^{\mathrm{b}}$ & $332 \pm 8^{\mathrm{a}}$ & $352 \pm 19^{\mathrm{a}}$ \\
Pancreas weight & $0.55 \pm 0.05$ & $0.78 \pm 0.11$ & $0.59 \pm 0.08$ & $0.67 \pm 0.09$ \\
Heart weight & $0.90 \pm 0.12$ & $1.36 \pm 0.50$ & $0.86 \pm 0.09$ & $1.08 \pm 0.09$ \\
Liver weight & $8.05 \pm 0.32^{\mathrm{a}}$ & $8.96 \pm 1.70^{\mathrm{b}}$ & $8.36 \pm 0.83^{\mathrm{c}}$ & $8.43 \pm 0.63^{\mathrm{c}}$ \\
Kidney weight & $2.30 \pm 0.21^{\mathrm{a}}$ & $2.56 \pm 0.44^{\mathrm{b}}$ & $2.31 \pm 0.23^{\mathrm{a}}$ & $2.40 \pm 0.13^{\mathrm{a}}$ \\
Spleen & $0.55 \pm 0.05$ & $0.70 \pm 1.01$ & $0.57 \pm 0.13$ & $0.62 \pm 0.09$ \\
\hline
\end{tabular}

Statistical analysis was by a one-way ANOVA with Tukey's test. All values are mean \pm standard error for rats in each group. Values with different superscripts are significantly different $(\mathrm{p}<0.05)$. STZ, streptozotocin. 
Table 4. Change of Serum glucose, GOT, GPT, ALP, BUN, and creatinine levels

\begin{tabular}{lcccc}
\hline \multicolumn{1}{c}{ Parameter } & Normal $(\mathrm{n}=5)$ & STZ $(\mathrm{n}=4)$ & STZ+rutin $(\mathrm{n}=7)$ & Rutin $(\mathrm{n}=6)$ \\
\hline GOT (U/L) & $129.60 \pm 20.45^{\mathrm{a}}$ & $309.75 \pm 51.37^{\mathrm{b}}$ & $210.83 \pm 60.83^{\mathrm{c}}$ & $129.00 \pm 33.60^{\mathrm{a}}$ \\
GPT (U/L) & $29.20 \pm 5.15^{\mathrm{a}}$ & $126.25 \pm 25.32^{\mathrm{b}}$ & $48.67 \pm 11.43^{\mathrm{c}}$ & $25.80 \pm 5.81^{\mathrm{a}}$ \\
ALP (U/L) & $518.20 \pm 72.94^{\mathrm{a}}$ & $880.75 \pm 65.24^{\mathrm{b}}$ & $503.50 \pm 66.74^{\mathrm{c}}$ & $503.40 \pm 49.78^{\mathrm{a}}$ \\
BUN (mg/dL) & $14.00 \pm 1.53^{\mathrm{a}}$ & $25.93 \pm 3.49^{\mathrm{b}}$ & $23.42 \pm 2.11^{\mathrm{c}}$ & $18.96 \pm 2.23^{\mathrm{a}}$ \\
Creatinine (mg/dL) & $0.50 \pm 0.03^{\mathrm{a}}$ & $0.52 \pm 0.05^{\mathrm{b}}$ & $0.46 \pm 0.03^{\mathrm{c}}$ & $0.48 \pm 0.04^{\mathrm{a}}$ \\
\hline
\end{tabular}

Statistical analysis was by a one-way ANOVA with Tukey's test. All values are mean \pm standard error for rats in each group. Values with different superscripts are significantly different $(\mathrm{p}<0.05)$. GOT, glutamic oxalaceic transaminase; GPT, glutamic pyruvic transaminase; ALP, alkaline phosphatase; BUN, blood urea nitrogen; STZ, streptozotocin.
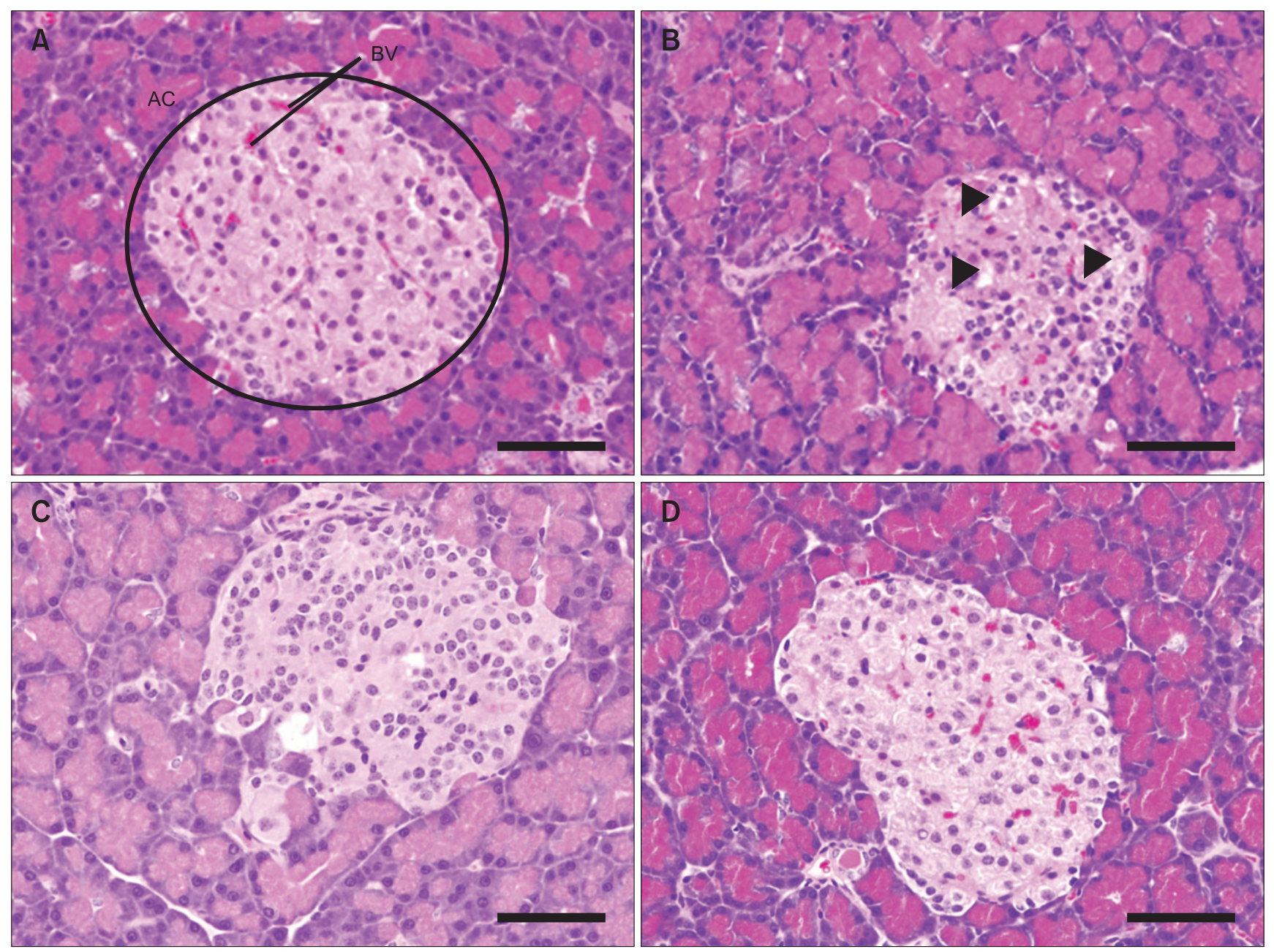

Fig. 1. Histopathologic changes of the pancreas (H\&E stain, scale bar=25 $\mu \mathrm{m}$ ). (A) In normal rat, the pancreas architectures were well preserved. Islet of Langerhans (circle). AC, acinar cells; BV, blood vessels. (B) In streptozotocin (STZ) treated rat, the destruction of insulin-producing $\beta$-cells and vacuoles were observed (arrowheads). (C) In STZ+rutin treated rat, the pancreas architectures were relatively well preserved. (D) In rutin treated rat, the pancreas architectures were well preserved.

did not decrease as much as those of the normal and rutintreated groups. Nonetheless, the values of the STZ+rutin group significantly decreased compared to those of the STZinduced diabetic group $(\mathrm{p}<0.05)$.

\section{Histological Observation}

According to the observation made through a light microscope, the shape of $\beta$-cell and acinar cell in the islet of Langerhans was normally preserved in the pancreas tissues 

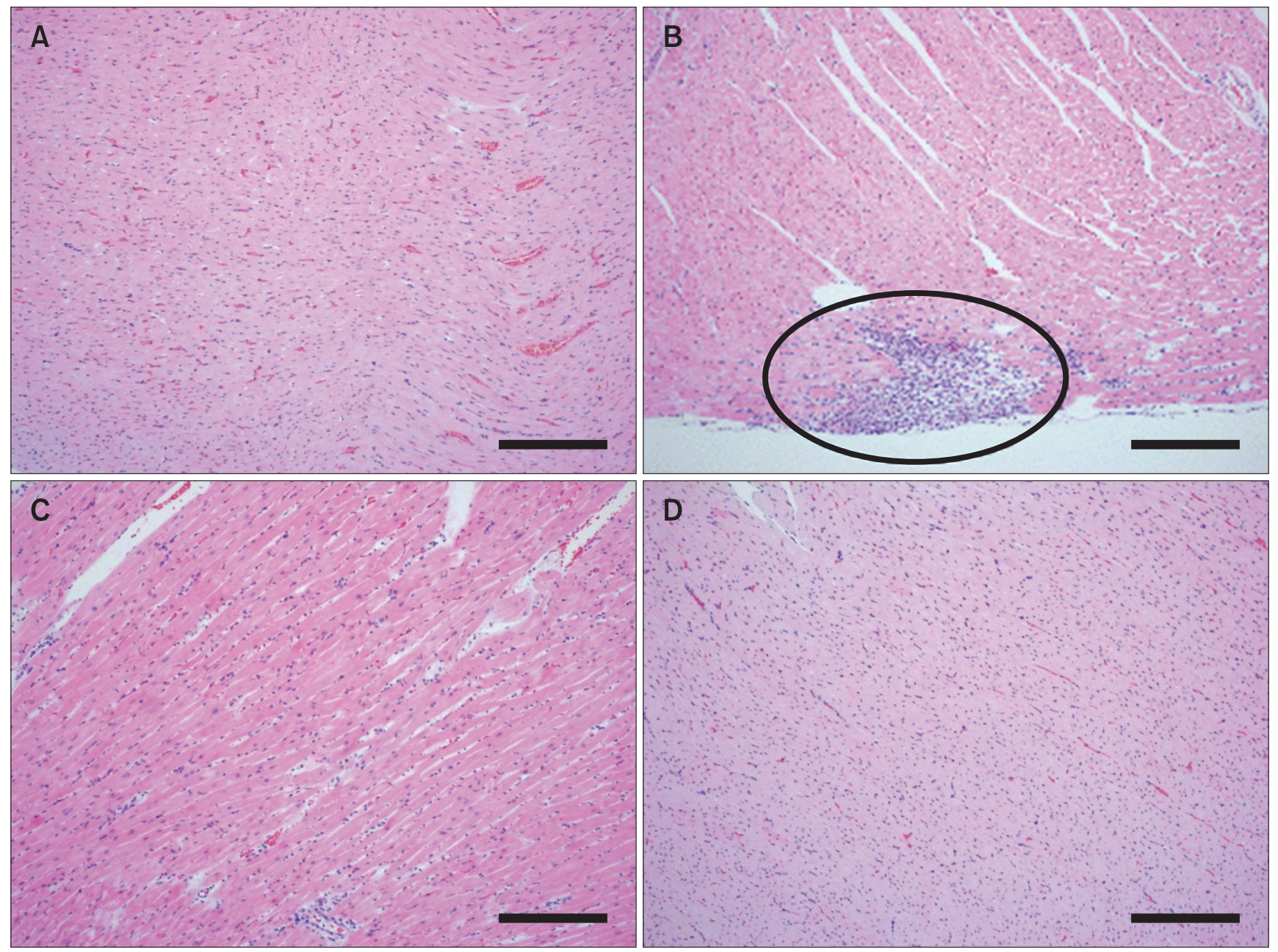

Fig. 2. Histopathologic changes of the heart (H\&E stain, scale bar=100 $\mu \mathrm{m}$ ). (A) In normal rat, the heart architectures were well preserved. (B) In streptozotocin (STZ) treated rat, the infiltration of inflammatory cells were observed (circle). (C) In STZ+rutin treated rat, the heart architectures were relatively well preserved. (D) In STZ+treated rat, the heart architectures were well preserved.

of the normal and rutin-treated groups (Fig. 1A and D). Meanwhile, STZ-treated groups showed destroyed $\beta$-cell and a big vacuole (Fig. 1B). For the STZ+rutin administered group, the $\beta$-cell was relatively normally preserved compared to that of the STZ-treated group and there was no vacuole (Fig. 1C).

The shape of the heart tissue in the normal and rutintreated groups was shown to be normal (Fig. 2A and D). Meanwhile, the STZ-treated group showed infiltration of the inflammatory cell (Fig. 2B). For the STZ+rutin-administered group, infiltration of the inflammatory cell was not observed; therefore, it showed relatively normally preserved shape compared to the heart tissue of the STZ-treated group (Fig. 2C).

The shape of the liver tissue in the normal and rutin-treated groups was shown to be normal (Fig. $3 \mathrm{~A}$ and D). Meanwhile, bullous degeneration and necrosis of liver cells were observed in the overall liver tissue in the STZ-treated groups (Fig. 3B). Since bullous degeneration and necrosis of liver cells were observed around the central vein in the STZ+rutin administered group, pathological opinion was decreased in general compared to the STZ-treated group (Fig. 3C).

The shape of the renal corpuscle and renal tubules in the kidney tissue was observed to be normal in the normal and rutin-treated groups (Fig. 4A and D). In the STZ-treated group, adhesion of the glomerulus and Bowman's capsule as well as intraluminal occlusion of the renal tubules appeared while noticeably showing infiltration of inflammatory cells (Fig. 4B). Since partial adhesion of the glomerulus and Bowman's capsule and infiltration of inflammatory cells were observed in the STZ+rutin administered group, pathological opinion was decreased in general compared to the STZtreated group (Fig. 4C).

When the spleen tissue was observed, it was not able to 

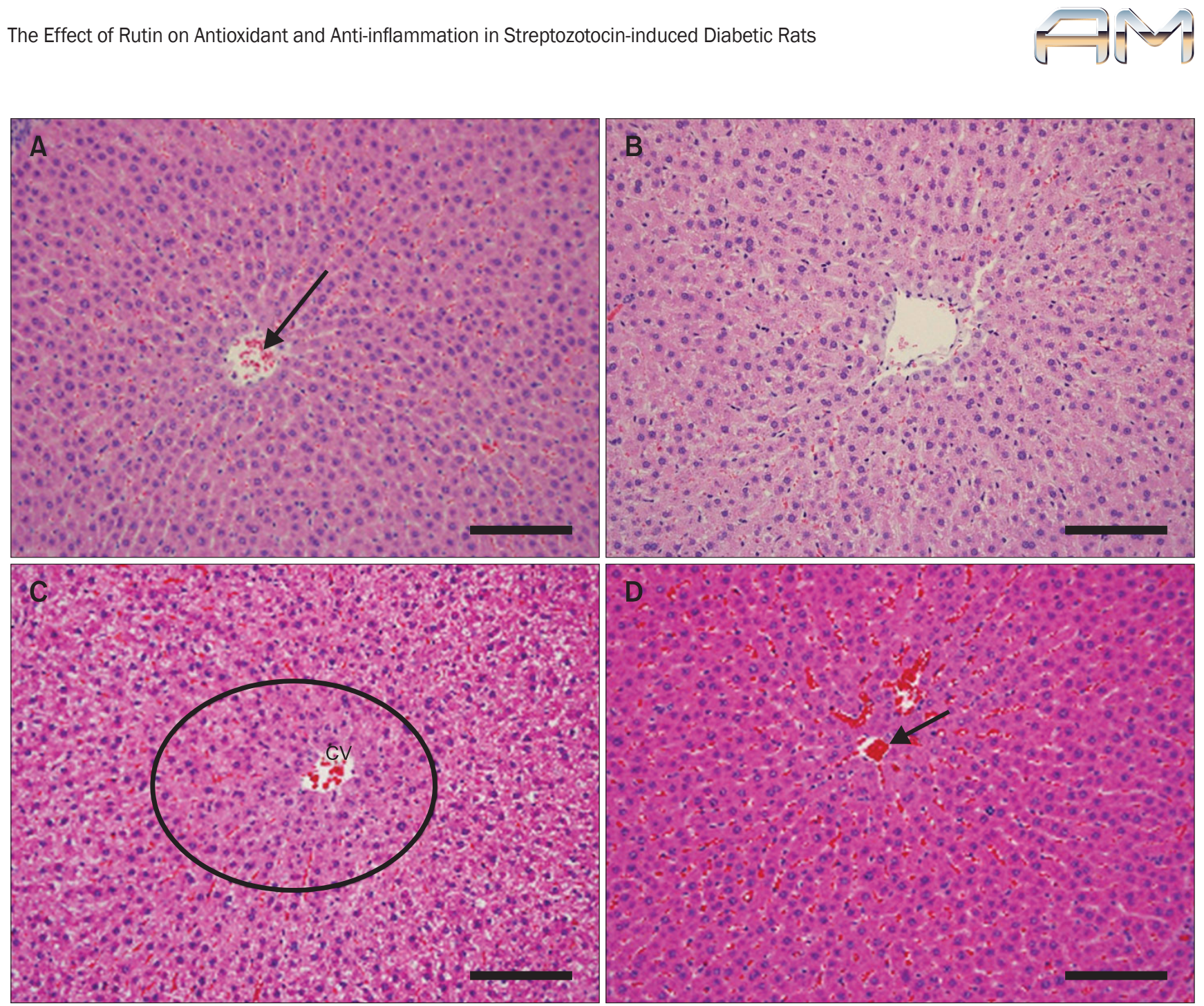

Fig. 3. Histopathologic changes of the liver (H\&E stain, scale bar=50 $\mu \mathrm{m})$. (A) In normal rat, the liver architectures were well preserved. The central vein (arrow) and normal hepatocytes were observed. (B) In streptozotocin (STZ) treated rat, hydropic degeneration and necrosis were observed overall. (C) In STZ+rutin treated rat, hydropic degeneration and necrosis were observed in the central vein (CV) around (circle). (D) In rutin treated rat, the liver architectures were well preserved. The central vein (arrow) and normal hepatocytes were observed.

observe any distinctive formative difference between the experiment groups as the white pulp in the spleen tissue was normally preserved within the red pulp (Fig. 5A-D).

When the retina tissue was observed, all 10 layers of the retina showed normally preserved shape in the normal and rutintreated groups (Fig. 6A and D). In the STZ-treated group, retinal detachment that separated the stratum pigmenti and layer of visual cells was observed (Fig. 6B). STZ+rutin administered group showed relatively normal shape compared to that of the STZ-treated group (Fig. 6C).

\section{DISCUSSION}

The reason why the STZ-induced diabetic group showed noticeably higher concentration of plasma glucose and serum glucose $(\mathrm{p}<0.05)$ is that the insulin secretion was impeded as STZ produced reactive oxygen species to repress the action of antioxidant system while causing oxidative damage to the pancreas $\beta$-cell (Szkudelski, 2001). Although the concentration levels of plasma glucose and serum glucose in the STZ+rutin-treated group were not reduced as much as that of the rutin-treated group, they were significantly decreased compared to the level of the STZ-induced diabetic group $(\mathrm{p}<0.05)$. Thus as shown in the report of Kamalakkannan \& Prince (2006), the concentration levels of plasma glucose and serum glucose were decreased as rutin removed free radicals and repressed lipid peroxidation while protecting the $\beta$-cell by impeding oxidative stress caused by STZ and increasing insulin secretion.

Meanwhile, the body weight of the STZ-induced diabetic group was noticeably decreased compared to the weight of the normal, STZ+rutin treated, and rutin-treated groups $(\mathrm{p}<0.05)$ 

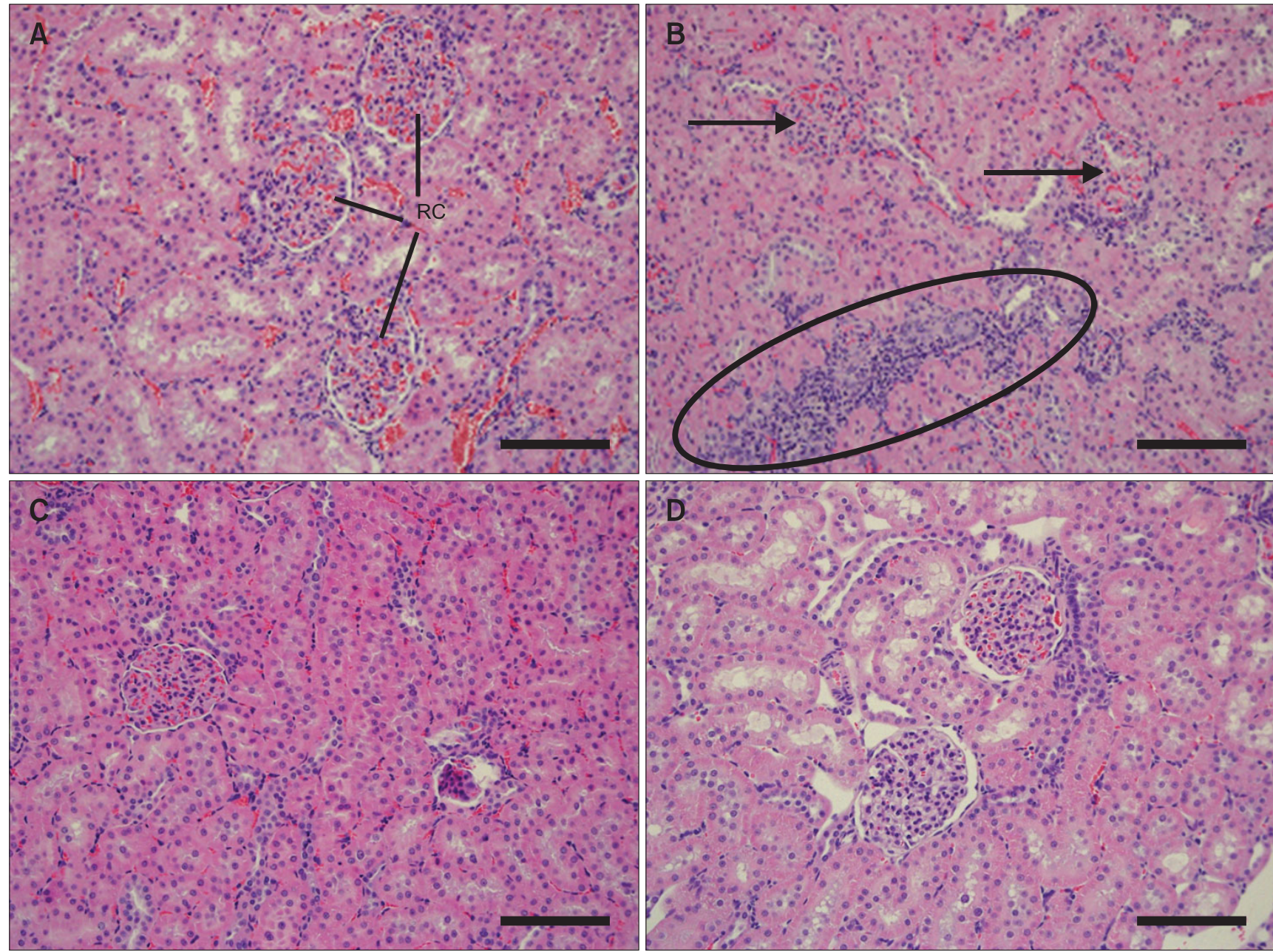

Fig. 4. Histopathologic changes of the kidney (H\&E stain, scale bar=50 $\mu \mathrm{m}$ ). (A) In normal rat, the kidney architectures were well preserved. The normal renal corpuscle (RC)s were observed. (B) In streptozotocin (STZ) treated rat, adhesion of glomerulus and Bowman's capsules and closing of uriniferous tubules' lumens were noted generally (arrows). The infiltration of inflammatory cells were observed (circle). (C) In STZ+rutin treated rat, the kidney architectures were relatively well preserved. Adhesion of glomerulus and Bowman's capsules and infiltration of inflammatory cells were observed partially. (D) In STZ+treated rat, the kidney architectures were well preserved.

due to abnormal energy metabolism caused by reduced glucose in the STZ-induced diabetic rats (Furuse et al., 1993). The weight of each organ in the STZ-induced diabetic group was shown to be higher compared to that of other groups and especially, the weight of liver and kidney showed significantly noticeable change among the organs $(\mathrm{p}<0.05)$. The significant change in the weight of liver and kidney among the STZinduced diabetic rats agreed with the results derived from other reports, as the kidney of the STZ-induced diabetic rats got bigger owing to the extracted glucose, accelerated cell division, and increased volume of the renal corpuscle (Gallaher et al., 1993). Meanwhile, the liver of the STZ-induced diabetic rats hypertrophied as lipid got accumulated in the liver due to abnormal glycometabolism and lipid metabolism (Grey et al., 1975; Dai et al., 1994). Among lipid metabolism, lipid peroxidation is a reaction that causes oxidative stress carried by polyunsaturated fatty acids, a type of free radical, and it can be repressed by an antioxidant (Korkina \& Afanas'ev, 1997).

As a result, GOT, GPT, and ALP were examined to measure liver function while BUN and creatinine were examined to measure kidney function. According to the result, the STZinduced diabetic group showed increased values in all areas compared to the values derived from other groups $(\mathrm{p}<0.05)$ and such result implies not only formative abnormality but also functional abnormality as well.

The weight of the STZ+rutin-treated group showed significant change compared to the weight of the STZ-induced diabetic group $(\mathrm{p}<0.05)$ because rutin repressed diabetes-triggered weight loss by impeding abnormal function of glucose metabolism. Meanwhile, the weight of liver and kidney in the STZ+rutin-treated group did not increased compared to the 

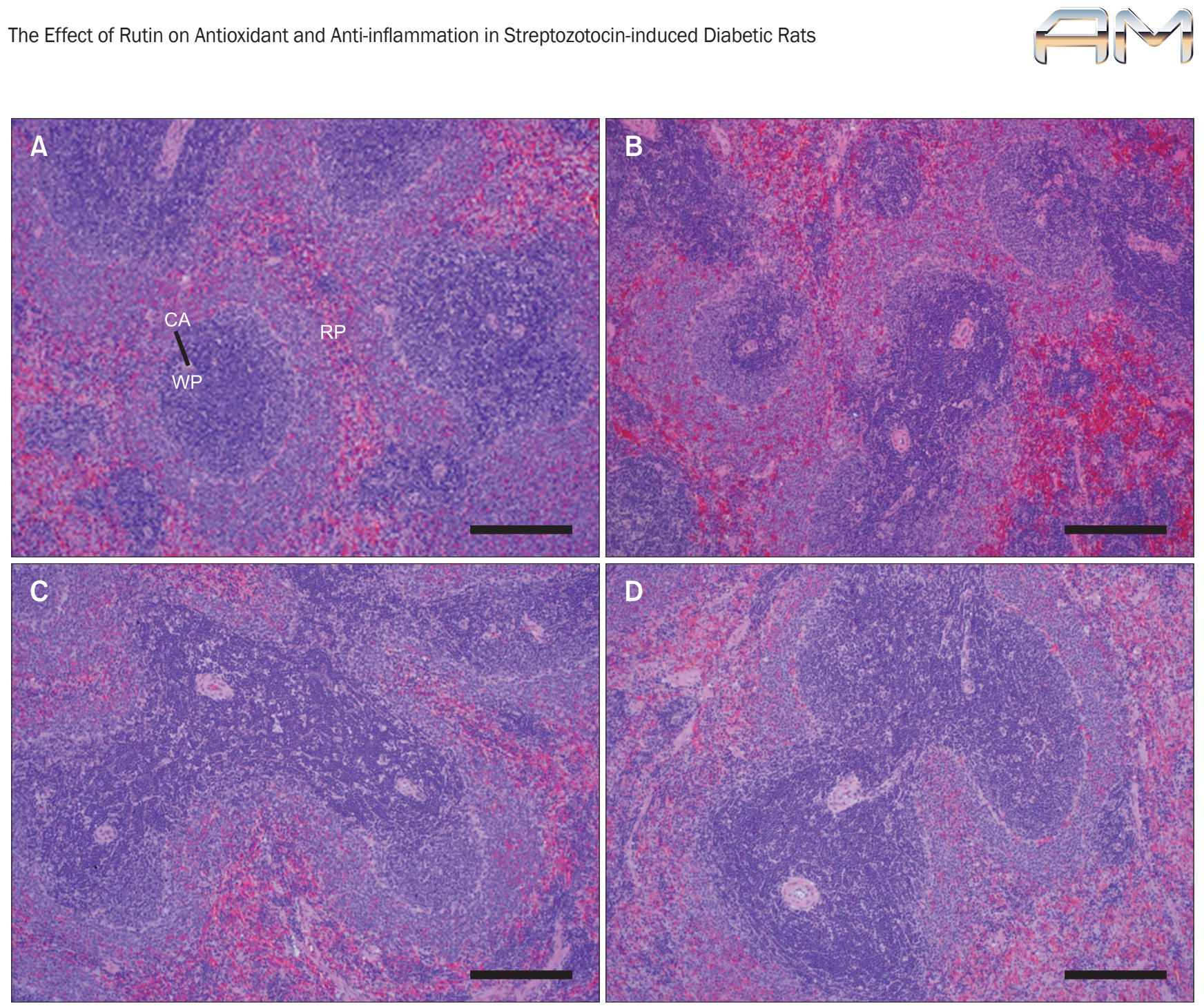

Fig. 5. Histopathologic changes of the spleen (H\&E stain, scale bar=100 $\mu \mathrm{m})$. (A) In normal rat, the spleen architectures were well preserved. CA, central artery; WP, white pulp; RP, red pulp. (B) In streptozotocin (STZ)-treated rat, the spleen architectures were well preserved. (C) In STZ+rutin treated rat, the spleen architectures were well preserved. (D) In rutin treated rat, the spleen architectures were well preserved.

weight of the STZ-induced diabetic group $(\mathrm{p}<0.05)$ because diabetic hypertrophy of the organs was repressed by the function of rutin. Through the effect of rutin, which has been reported to remove free radicals (Ferrali et al., 1997), vitalize antioxidant enzyme (Elliott et al., 1992), and repress lipid peroxidation in vitro (Kozlov et al., 1994), it is thought that the diabetic symptoms that were induced by STZ were alleviated. According to the results derived from the measurement of GOT, GPT, ALP, BUN and creatinine, the values obtained from the STZ+rutin-treated group were not reduced as much as those from the normal and rutin-treated groups. However, such values were significantly decreased compared to those of the STZ-induced diabetic group $(\mathrm{p}<0.05)$; thus, rutin is believed to functionally alleviate diabetic symptoms.

In the pancreas tissue of the STZ-treated group, the destruction of $\beta$-cell and formation of a big vacuole were noticeably observed (Ahmed et al., 1998). It is because STZ created reactive oxygen species and repressed the antioxidant defense system to cause oxidative damage to the pancreas $\beta$-cell (Szkudelski, 2001). The $\beta$-cell in the STZ+rutin-administered group was relatively normally preserved and a vacuole was not observed. Such result was attributed to the cell-protecting effect by rutin's antioxidant activities. In the heart tissue of the STZ-treated group, infiltration of inflammatory cell was noticeably observed (Doi et al., 2001) while showing bullous degeneration and necrosis of liver cells throughout the liver cells (Evelson et al., 2005). In the kidney tissue, adhesion of the glomerulus and Bowman's capsule, intraluminal occlusion of the renal tubules, and infiltration of inflammatory cells were clearly observed (Kang et al., 2005). Retinal detachment that separated the stratum pigmenti and layer of visual cells was also observed (Fletcher et al., 2007). These are the typical formative changes that indicate occurrence of inflammation in the heart, liver, kidney, and retina tissues. It is known that 

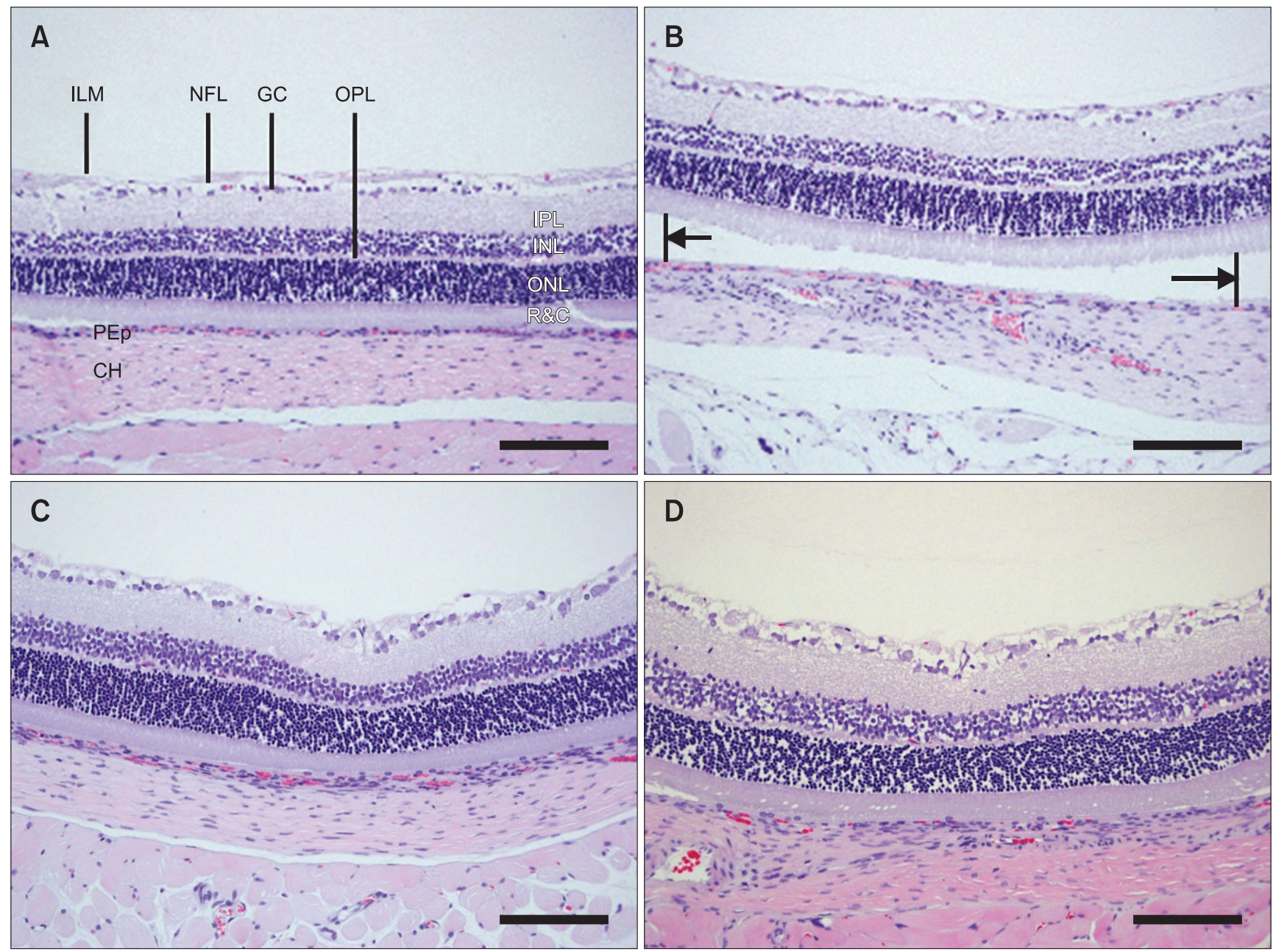

Fig. 6. Histopathologic changes of the retina (H\&E stain, scale bar=50 $\mu \mathrm{m}$ ). (A) In normal rat, the retina architectures were well preserved. ILM, internal limiting membrane; NFL, nerve fiber layer; GC, layer of ganglion cells; OPL, outer plexiform layer; IPL, inner plexiform layer; INL, inner nuclear layer; ONL, outer nuclear layer; R\&C, layer of rod and cones; PEp, pigment epithelium; CH, choroid. (B) In streptozotocin (STZ)-treated rat, the retinal detachment (arrows) and separation of pigment epithelium and layer of optic cells were observed. (C) In STZ+rutin treated rat, the retina architectures were relatively well preserved. (D) In rutin treated rat, the retina architectures were well preserved.

chemical inflammatory media are secreted from various cells including fat cells under hyperglycemia state (Guha et al., 2000; Lin et al., 2001; Aronson et al., 2004) and by the secreted inflammatory factors, diabetic complications such as cardiovascular diseases (Calles-Escandon \& Cipolla, 2001; Dandona et al., 2003; Tracy, 2003; Widlansky et al., 2003), microalbuminuria (Gomes \& Nogueira, 2004), and diabetic retinopathy (Izuora et al., 2005) are thought to be generated. Such findings support the histopathologic outcomes of the study. Also, Zhou et al. (2010) found two genes that could control inflammation and diabetes simultaneously and reported that hyperglycemia was repressed when the secretion of IL-1, which was cytokine related to inflammation, was impeded by the action of these genes in cells. Such finding revealed the correlation between diabetes and inflammatory response. In the STZ+rutin administered group, the heart and retina tissues were shown to be in relatively normally preserved form. In the liver tissue, bullous degeneration and necrosis of liver cells were observed only at the central vein while showing partial adhesion of glomerulus and Bowman's capsule as well as partially infiltrated inflammatory cells in the kidney tissue. As such, results imply that pathological opinion for the STZ+rutin-administered group decreased in general compared to the STZ-treated group. Meanwhile, spleen is an organ with countless blood vessels like heart, liver, and kidney; thus, the experiment was conducted with an assumption that spleen was damaged under hyperglycemia state. However, a distinctive formative difference could not be found in all groups. Therefore, it is believed that spleen was intact against hyperglycemia.

These are the effects of rutin including antioxidant activities, anti-inflammatory effects (Aleksandrov et al., 1986), myocardial 
protection (Pozin et al., 1996), and hepatoprotective activities (Janbaz et al., 2002). It is believed that rutin displayed protective effects for various organs in the STZ-induced diabetic rats through dynamic medical actions. Also, according to a report, antioxidants impede inflammation (Cuzzocrea et al., 2001) and it is known that the anti-oxidative activity and antiinflammatory effects of rutin are not an independent function.

\section{CONCLUSIONS}

In the STZ-induced diabetic rats, blood glucose level was decreased by the antioxidant activities and anti-inflammatory effects of rutin. Also, the pancreas, heart, liver, kidney, and retina tissues that were related to diabetic complications were functionally and formatively protected by rutin. Therefore, it is suggested to apply rutin clinically for the treatment of diabetes and its complications.

\section{REFERENCES}

Ahmed I, Adeghate E, Sharma A K, Pallot D J, and Singh J (1998) Effects of Momordica charantia fruit juice on islet morphology in the pancreas of the streptozotocin-diabetic rat. Diabetes Res. Clin. Pract. 40, 145-151.

Aleksandrov P N, Speranskaia T V, Bobkov lu G, Zagorevskil V A, and Zykov D A (1986) Effect of rutin and esculamine on models of aseptic inflammation. Farmakol. Toksikol. 49, 84-86.

Aronson D, Bartha P, Zinder O, Kerner A, Markiewicz W, Avizohar O, Brook G J, and Levy Y (2004) Obesity is the major determinant of elevated C-reactive protein in subjects with the metabolic syndrome. Int. J. Obes. Relat. Metab. Disord. 28, 674-679.

Baynes J W (1991) Role of oxidative stress in development of complications in diabetes. Diabetes 40, 405-412.

Bear W L and Teel R W (2000) Effects of citrus flavonoids on the mutagenicity of heterocyclic amines and on cytochrome P450 1A2 activity. Anticancer Res. 20, 3609-3614.

Calles-Escandon J and Cipolla M (2001) Diabetes and endothelial dysfunction: a clinical perspective. Endocr. Rev. 22, 36-52.

Chen S, Gong J, Liu F, and Mohammed U (2000) Naturally occurring polyphenolic antioxidants modulate IgE-mediated mast cell activation. Immunology 100, 471-480.

Coppey L J, Gellett J S, Davidson E P, Dunlap J A, Lund D D, and Yorek M A (2001) Effect of antioxidant treatment of streptozotocin-induced diabetic rats on endoneurial blood flow, motor nerve conduction velocity, and vascular reactivity of epineurial arterioles of the sciatic nerve. Diabetes 50, 1927-1937.

Craig W J (1999) Health-promoting properties of common herbs. Am. J. Clin. Nutr. 70, 491S-499S.

Cuzzocrea S, Riley D P, Caputi A P, and Salvemini D (2001) Antioxidant therapy: a new pharmacological approach in shock, inflammation, and ischemia/reperfusion injury. Pharmacol. Rev. 53, 135-159.

Dai S, Thompson K H, and McNeill J H (1994) One-year treatment of streptozotocin-induced diabetic rats with vanadyl sulphate. Pharmacol. Toxicol. 74, 101-109.

Dandona P, Aljada A, Chaudhuri A, and Bandyopadhyay A (2003) The potential influence of inflammation and insulin resistance on the pathogenesis and treatment of atherosclerosis-related complications in type 2 diabetes. J. Clin. Endocrinol. Metab. 88, 2422-2429.

Deschner E E, Ruperto J, Wong G, and Newmark H L (1991) Quercetin and rutin as inhibitors of azoxymethanol-induced colonic neoplasia. Carcinogenesis 12, 1193-1196.

Di Carlo G, Autore G, Izzo A A, Maiolino P, Mascolo N, Viola P, Diurno M V, and Capasso $F(1993)$ Inhibition of intestinal motility and secretion by flavonoids in mice and rats: structure-activity relationships. $J$. Pharm. Pharmacol. 45, 1054-1059.

Doi K, Sawada F, Toda G, Yamachika S, Seto S, Urata Y, Ihara Y, Sakata N, Taniguchi N, Kondo T, and Yano K (2001) Alteration of antioxidants during the progression of heart disease in streptozotocin-induced diabetic rats. Free Radic. Res. 34, 251-261.

Elliott A J, Scheiber S A, Thomas C, and Pardini R S (1992) Inhibition of glutathione reductase by flavonoids. A structure-activity study. Biochem. Pharmacol. 44, 1603-1608.

Evelson P, Susemihl C, Villarreal I, Llesuy S, Rodríguez R, Peredo H, Lemberg A, Perazzo J, and Filinger E (2005) Hepatic morphological changes and oxidative stress in chronic streptozotocin-diabetic rats. Ann. Hepatol. 4, 115-120.

Ferrali M, Signorini C, Caciotti B, Sugherini L, Ciccoli L, Giachetti D, and Comporti M (1997) Protection against oxidative damage of erythrocyte membrane by the flavonoid quercetin and its relation to iron chelating activity. FEBS Lett. 416, 123-129.

Fletcher E L, Phipps J A, Ward M M, Puthussery T, and Wilkinson-Berka $J$ L (2007) Neuronal and glial cell abnormality as predictors of progression of diabetic retinopathy. Curr. Pharm. 26, 2699-2712.

Furuse M, Kimura C, Mabayo R T, Takahashi H, and Okumura J (1993) Dietary sorbose prevents and improves hyperglycemia in genetically diabetic mice. J. Nutr. 123, 59-65.

Gallaher D D, Csallany A S, Shoeman D W, and Olson J M (1993) Diabetes increases excretion of urinary malonaldehyde conjugates in rats. Lipids 28, 663-666.

Gao Z, Xu H, and Huang K (2002) Effects of rutin supplementation on antioxidant status and iron, copper, and zinc contents in mouse liver and brain. Biol. Trace. Elem. Res. 88, 271-279.

Gomes M B and Nogueira V G (2004) Acute-phase proteins and microalbuminuria among patients with type 2 diabetes. Diabetes Res. Clin. Pract. 66, 31-39.

Grey N J, Karl I, and Kipnis D M (1975) Physiologic mechanisms in the development of starvation ketosis in man. Diabetes 24, 10-16.

Guha M, Bai W, Nadler J L, and Natarajan R (2000) Molecular mechanisms of tumor necrosis factor alpha gene expression in monocytic cells via hyperglycemia-induced oxidant stress-dependent and -independent pathways. J. Biol. Chem. 275, 17728-17739.

Huang W Y, Zhang H C, Liu W X, and Li C Y (2012) Survey of antioxidant capacity and phenolic composition of blueberry, blackberry, and strawberry in Nanjing. J. Zhejiang Univ. Sci. B 13, 94-102. 
Izuora K E, Chase H P, Jackson W E, Coll J R, Osberg I M, Gottlieb P A, Rewers M J, and Garg S K (2005) Inflammatory markers and diabetic retinopathy in type 1 diabetes. Diabetes Care 28, 714-715.

Janbaz K H, Saeed S A, and Gilani A H (2002) Protective effect of rutin on paracetamol- and $\mathrm{CCl} 4$-induced hepatotoxicity in rodents. Fitoterapia 73, 557-563.

Kamalakkannan N and Prince P S (2006) Antihyperglycaemic and antioxidant effect of rutin, a polyphenolic flavonoid, in streptozotocininduced diabetic wistar rats. Basic Clin. Pharmacol. Toxicol. 98, 97103.

Kang J, Dai X S, Yu T B, Wen B, and Yang Z W (2005) Glycogen accumulation in renal tubules, a key morphological change in the diabetic rat kidney. Acta. Diabetol. 42, 110-116.

Korkina L G and Afanas'ev I B (1997) Antioxidant and chelating properties of flavonoids. Adv. Pharmacol. 38, 151-163.

Kozlov A B, Ostrachovitch E A, and Afanas'ev I B (1994) Mechanism of inhibitory effects of chelating drugs on lipid peroxidation in rat brain homogenates. Biochem. Pharmacol. 47, 795-799.

Kreft S, Knapp M, and Kreft I (1999) Extraction of rutin from buckwheat (Fagopyrum esculentumMoench) seeds and determination by capillary electrophoresis. J. Agric. Food Chem. 47, 4649-4652.

Lin Y, Rajala M W, Berger J P, Moller D E, Barzilai N, and Scherer P E (2001) Hyperglycemia-induced production of acute phase reactants in adipose tissue. J. Biol. Chem. 276, 42077-42083.

Nagasawa T, Tabata N, Ito Y, Aiba Y, Nishizawa N, and Kitts D D (2003a) Dietary G-rutin suppresses glycation in tissue proteins of streptozotocin-induced diabetic rats. Mol. Cell Biochem. 252, 141147.

Nagasawa T, Tabata N, Ito Y, Nishizawa N, Aiba Y, and Kitts D D (2003b) Inhibition of glycation reaction in tissue protein incubations by water soluble rutin derivative. Mol. Cell Biochem. 249, 3-10.

Potter J D (1997) Cancer prevention: epidemiology and experiment.
Cancer Lett. 114, 7-9.

Pozin V M, Skuratovskaia S G, and Pocheptsova G A (1996) Changes in the vascular wall and ischemic damages to the myocardium in reversible episodes of heart muscle ischemia. Fiziol. Zh. 42, 10-16.

Rayfield E J and Ishimura K (1987) Environmental factors and insulindependent diabetes mellitus. Diabetes Metab. Rev. 3, 925-957.

Rice-Evans C and Packer L (1998) In Flavonoids in Health and Diseases (Marcel Decker Inc., New York).

Simpson R W, Shaw J E, and Zimmet P Z (2003) The prevention of type2diabetes - lifestyle change or pharmacotherapy? A challenge for the 21st century. Diabetes Res. Clin. Pract. 59, 165-180.

Szkudelski T (2001) The mechanism of alloxan and streptozotocin action in B cells of the rat pancreas. Physiol. Res. 50, 537-546.

Tracy R P (2003) Inflammation, the metabolic syndrome and cardiovascular risk. Int. J. Clin. Pract. Suppl. 134, 10-17.

West K M, Ahuja M M, Bennett P H, Czyzyk A, De Acosta O M, Fuller J H, Grab B, Grabauskas V, Jarrett R J, and Kosaka K (1983) The role of circulating glucose and triglyceride concentrations and their interactions with other "risk factors" as determinants of arterial disease in nine diabetic population samples from the WHO multinational study. Diabetes Care 6, 361-369.

Widlansky M E, Gokce N, Keaney J F Jr, and Vita J A (2003) The clinical implications of endothelial dysfunction. J. Am. Coll. Cardiol. 42, 11491160.

World Health Organization/International Diabetes Federation (1999) The Economics of Diabetes and Diabetes Care - A Report of the Diabetes Health Economics Study Group. World Health Organization/ International Diabetes Federation WHO, Geneva.

Zhou R, Tardivel A, Thorens B, Choi I, and Tschopp J (2010) Thioredoxininteracting protein links oxidative stress to inflammasome activation. Nat. Immunol. 11, 136-140. 